\title{
Experimental Determination of the Kinetics of Glauconite Dissolution and Carbonation
}

\author{
QIN ZHANG ${ }^{1}$ AND BENJAMIN TUTOLO $^{2}$ \\ ${ }^{1}$ University of Calgary \\ ${ }^{2}$ University of Calgary, Department of Geoscience \\ Presenting Author: qin.zhang1@ucalgary.ca
}

Geologic carbon storage (GCS) in sedimentary basins is a promising method for $\mathrm{CO}_{2}$ disposal due to the global distribution of sedimentary basins with pre-existing injection infrastructure. Determination of mineral dissolution and precipitation kinetics is critical to the successful disposal of $\mathrm{CO}_{2}$ in reservoirs because the storage capacity is determined by the conversion rates of $\mathrm{CO}_{2}$ to carbonate minerals [1]. Glauconite carbonation has been suggested as an important mechanism for GCS, however, previous research has invariably suffered from the almost completely unconstrained rates of glauconite dissolution and carbonation under relevant conditions [2]. Modeling studies thus applied the kinetics of other clays as proxies for glauconite, such assumptions could lead to a vast range of uncertainties, which will be compounded when coupled to carbonate precipitation.

To fill this significant knowledge gap, we have undertaken a study to quantify the rates of glauconite dissolution and carbonation. We developed a new, mixed-flow reactor apparatus to explore the kinetics of glauconite dissolution under strictly controlled anaerobic conditions at $\mathrm{pH}$ ranging from 2 to 10 and temperatures ranging from 24 to $60{ }^{\circ} \mathrm{C}$. Temporal evolution of the differences between the inlet and outlet solution aqueous cation concentrations during glauconite dissolution experiments have been analyzed using inductively coupled plasma-optical emission spectrometry (ICP-OES). BET surface area-normalized rates exhibit stoichiometric or close-to-stoichiometric glauconite dissolution for all elements except for Al. The carbonation reactions occurred at $60{ }^{\circ} \mathrm{C}$ with 60 bars of $\mathrm{CO}_{2}$ in a $100 \mathrm{ml}$ Parr pressurized reactor vessel, which was constantly stirred and kept at a constant temperature by a Parr controlled furnace. The reacting fluid was sampled regularly and analyzed with ICPOES. The kinetic data we present will provide vital insights in the development of quantitative reactive-transport models to predict the fate of $\mathrm{CO}_{2}$ in glauconite-bearing GCS reservoirs.

[1] Matter, \& Kelemen (2009), Nat. Geosci. 2, 837-841.

[2] Xu, Apps \& Pruess (2004), Appl. Geochemistry 19, 917936. 